\title{
Resistivity structure in the western part of the fault rupture zone associated with the 1999 İzmit earthquake and its seismogenic implication
}

\author{
S. B. Tank ${ }^{1}$, Y. Honkura ${ }^{1}$, Y. Ogawa ${ }^{2}$, N. Oshiman ${ }^{3}$, M. K. Tunçer ${ }^{4}$, M. Matsushima ${ }^{1}$, C. Çelik ${ }^{4}$, E. Tolak ${ }^{4}$, and A. M. Iş̧ıara ${ }^{4}$ \\ ${ }^{1}$ Department of Earth and Planetary Sciences, Tokyo Institute of Technology, Tokyo, Japan \\ ${ }^{2}$ Volcanic Fluid Research Center, Tokyo Institute of Technology, Tokyo, Japan \\ ${ }^{3}$ Disaster Prevention Research Institute, Kyoto University, Kyoto, Japan \\ ${ }^{4}$ Kandilli Observatory and Earthquake Research Institute, Boğaziçi University, Istanbul, Turkey
}

(Received February 12, 2003; Revised June 26, 2003; Accepted July 2, 2003)

\begin{abstract}
Magnetotelluric (MT) surveys were carried out along some profiles crossing the fault rupture zone associated with the İzmit earthquake which took place on 17 August 1999 in the western part of the North Anatolian Fault Zone (NAFZ). In this paper, we focus on the western part of the fault rupture zone where two different groups of seismicity followed the İzmit earthquake. One group was seen along a narrow belt and corresponds to aftershocks occurring along the fault rupture zone. The other was seen in a circular region and represents a swarm activity, presumably triggered by the occurrence of the İzmit earthquake. Two-dimensional inversion was performed for the MT data acquired along two profiles; one crosses the western end of the fault rupture zone and the other is located in the west of the swarm activity area. In the former case, aftershocks tended to occur in a resistive zone underlain by a moderately conductive zone, as was the case for the hypocenter area. In the latter case, the swarm activity tends to be confined in a conductive zone below a highly resistive zone. This activity is likely to be triggered through pore-pressure changes associated with the İzmit earthquake.
\end{abstract}

Key words: Magnetotellurics, resistivity structure, İzmit earthquake, North Anatolian Fault Zone, seismogenic zone.

\section{Introduction}

In recent years, particular attention has been paid to the possible role of crustal fluid in the generation of earthquakes (e.g. Zhao et al., 1996). Magnetotellurics (MT) is an efficient method in sensing the crustal resistivity structure which reflects fluids in the crust. Recent dense MT measurements in the vicinity of active faults indicate that seismic activity clusters near the rims of low resistivity zones (Unsworth $e t$ al., 2000; Mitsuhata et al., 2001; Ogawa et al., 2001, 2002; Kasaya et al., 2002). In this paper, we focus our attention on a possible relation between the resistivity structure and seismic activity for the two profiles shown in Fig. 1, in which another profile crossing the main shock area near İzmit (Honkura et al., 2000; Oshiman et al., 2002) is also shown.

Some other MT studies in Turkey mainly focused on more regional studies especially in the western and northwestern parts of the country with sparse station distributions, aiming at discussing the tectonic implications. Çağlar (2001) investigated the resistivity structure for the Sakarya and Bornova zones in western Turkey. Bayrak and Nalbant (2001) similarly studied a region close to the area investigated by Çağlar (2001). They pointed out that the lithosphere/asthenosphere boundary is shallow in western Turkey and it undulates between 30 to $50 \mathrm{~km}$. Both studies showed that there is a widespread conductor in western Turkey, reflecting partial melting at the lithosphere/asthenosphere boundary. Another

Copy right (C) The Society of Geomagnetism and Earth, Planetary and Space Science (SGEPSS); The Seismological Society of Japan; The Volcanological Society of Japan; The Geodetic Society of Japan; The Japanese Society for Planetary Sciences. study was performed by Gürer (1996) near the epicentral region of the İzmit earthquake.

In view of the westward migrating nature of the major earthquakes along the North Anatolian Fault Zone (NAFZ), much attention has been paid to the westward extension of the İzmit earthquake rupture zone and, hence, we made wideband $(320-0.001 \mathrm{~Hz})$ MT surveys along two profiles in this area in 2001 and 2002.

The aftershock activity of the 17 August 1999 İzmit earthquake shows a clear linear clustering toward the west, but further to the west in the Armutlu Peninsula, there is a swarm area which is circular rather than linear (Barıs et al., 2002; Ito et al., 2002), as shown in Fig. 2. The locations of the two profiles in this study were chosen according to the characteristics of seismic activity. The northern branch of the NAFZ passes through the northern side of profile 1, as shown in Figs. 1 and 2, where aftershocks occurred along a linear trend. The profile 2 was intended to cross the swarm area, but we were obliged to shift the profile somewhat to the west, because of difficult access to this steep mountainous area. However, the swarm activity tended to spread toward the profile (Ito et al., 2002) and, hence, the resistivity structure beneath this profile is likely to represent the structure in the swarm area.

In this paper, we try to examine and discuss on the relation between the seismic activity and the resistivity structure on the basis of the results for profiles 1 and 2 shown in Fig. 1. We also refer to the result obtained for the profile crossing the main shock area (Honkura et al., 2000; Oshiman et al., 2002). 


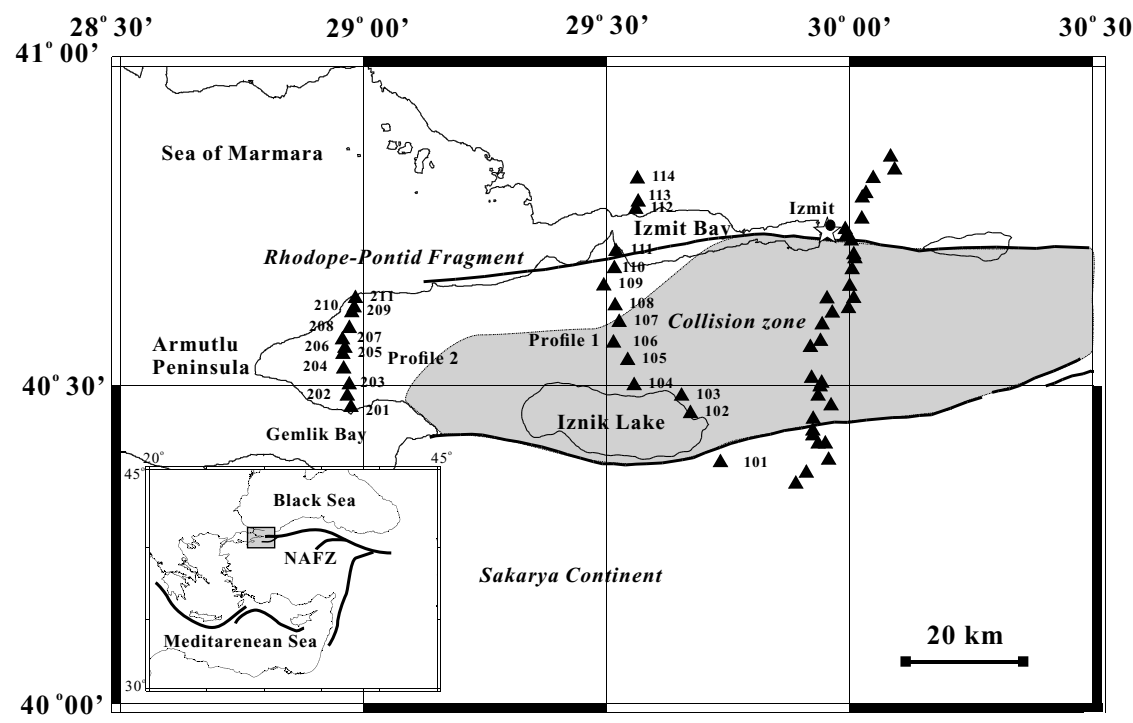

Fig. 1. Location of MT survey area in the western part of the North Anatolian Fault Zone (NAFZ). Triangles with numbers show the MT measurement sites along profiles 1 and 2. Triangles without site numbers indicate the previous profile (Honkura et al., 2000; Oshiman et al., 2002). The solid lines show the two major branches of the NAFZ in this area. The collision zone between the Rhodope-Pontid fragment in the north and the Sakarya continent in the south is shown by a shaded area.

\section{$\mathbf{2 8}^{\circ} \mathbf{3 0}$,}

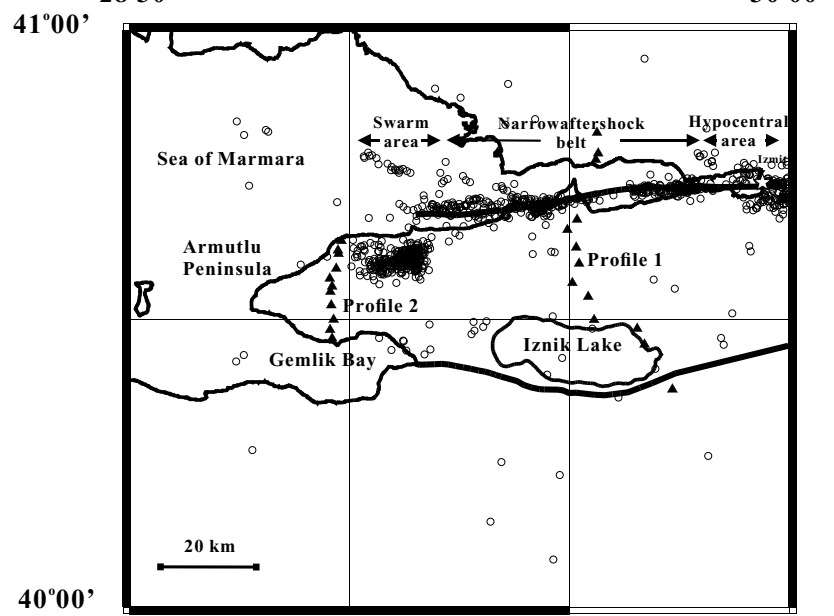

Fig. 2. Distribution of small earthquakes during the period from the main shock of the İzmit earthquake (August 17) to the end of September 1999 (Ito et al., 2002). They are classified into three groups; the aftershock area in the vicinity of the hypocenter, the linear aftershock belt, and the swarm area.

\section{Tectonic Setting of the Survey Areas}

The survey area, including the Armutlu peninsula, is interesting seismotectonically because it lies between the two main branches of the NAFZ (Yilmaz et al., 1995); part of the northern branch was ruptured in association with the İzmit earthquake, while the southern one remains unruptured. Geologically, however, this area is complex because three major zones mainly form the Armutlu peninsula: the northern zone characterized by the Rhodope-Pontide fragment (representing the southern part of Laurasia), the central zone (the ocean floor of the northern branch of Neo-Tethyan Ocean), and the southern zone by the Sakarya continent (representing a fragment of the Gondwanaland).

This area was a collision zone that took place between the
Sakarya continent and the Rhodope-Pontide fragment during the late Cretaceous. The north margin of the Sakarya continent went down the Rhodope-Pontide fragment, experiencing some deformation that increased progressively. As the collision advanced, an ophiolitic slab, which was detached from its root moving southwards, went over the subducting Sakarya continent. Tectonic activity on both of the continents resulted in thrusting and tight folding. Heavy nappes caused the edge of the Sakarya continent to subside, which was followed by the formation of faults and metamorphism. Finally, the area was covered with marine sediments (Y1lmaz et al., 1995).

\section{Profile 1 (narrow aftershock belt)}

Profile 1 consists of 14 wide-band MT sites that were deployed in two campaigns in 2001 and 2002. Site separation is about 2 to $3 \mathrm{~km}$ along the profile except in the İzmit Bay area. This profile cuts two different geologic zones, the northern (Rhodope-Pontide fragment) and the central zones among the three zones forming the Armutlu Peninsula.

\section{Profile 2 (swarm area)}

Profile 2 is located further west in the Armutlu Peninsula. This profile is on the northern geological zone and limited by the Sea of Marmara in the north and Gemlik Bay in the south. In the year 2001, we made wide-band MT measurements at 11 sites which are more densely distributed, compared with profile 1.

The MT data were obtained with Phoenix Geophysics Ltd. MTU-5/2E systems. At all of the sites, two components of the electric fields $\left(E_{x}, E_{y}\right)$ and at most of the sites, three components of the magnetic field $\left(H_{x}, H_{y}, H_{z}\right)$ were recorded.

\section{Analyses}

The data quality turned out to be good in general, but we applied the remote reference data processing technique (Gamble et al., 1979) in order to reduce possible effects of 


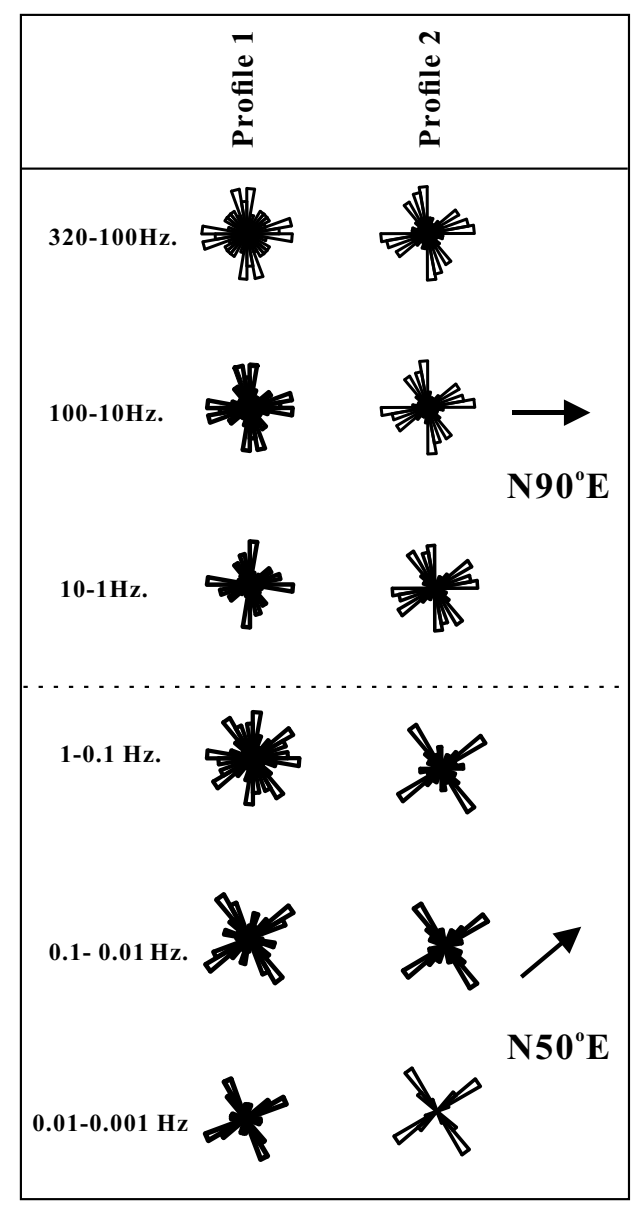

Fig. 3. Rose diagrams showing the histograms of the geoelectrical strike from the tensor decomposition for the two profiles, respectively. They are divided into two types for different frequency bands: $\mathrm{N} 90^{\circ} \mathrm{E}$ for the high frequency band and $\mathrm{N} 50^{\circ} \mathrm{E}$ for the low frequency band.

noise. This was required especially for the sites that are located on the northern sides of both profiles, where the noise level was somewhat higher. In order to check the twodimensionality of the structure, we performed Groom-Bailey decompositions (Groom and Bailey, 1989) where decomposition parameters were site and period-dependent. The frequency range was chosen to be between 320 and $0.001 \mathrm{~Hz}$. In both profiles, high and low frequency data tend to show similar strike angles, as shown in Fig. 3. The high frequency (320-1 Hz) data for both profiles were dominated by a strike angle of $\mathrm{N} 90^{\circ} \mathrm{E}$, which seems to be under the influence of a strike angle probably controlled by the presence of the fault. On the other hand, the strike angle for the low frequency $(1-0.001 \mathrm{~Hz})$ data showed $\mathrm{N} 50^{\circ} \mathrm{E}$ that is consistent with the regional geology. In fact, this angle is parallel to the collision boundary between the continents. Also, several days after the mainshock of the İmit earthquake, some aftershocks occurred in alignment with the southwest-northeast direction (Ito et al., 2002), suggesting a similar seismotectonic regional strike.

After all, $\mathrm{N} 50^{\circ} \mathrm{E}$ was chosen as the strike angle, since we payed more attention to the deeper structure. The GroomBailey decomposition was performed again with this angle and, hence, the profiles were projected onto the direction perpendicular to the strike. A two-dimensional inversion
(Ogawa and Uchida, 1996) was performed using the apparent resistivity and phase data in the transverse magnetic (TM) and transverse electric (TE) modes. The error floor during the inversions was taken as $10 \%$. The root mean square value was 2.8 for profile 1 and 2.7 for profile 2 . Since the study area is surrounded by the Sea of Marmara, the known ocean bathymetry was two-dimensionally included in the models during the inversions, except for the southern end of profile 2.

Figures 4(a) and 4(b) show the comparisons between the observed and the calculated apparent resistivity and phase for profiles 1 and 2, respectively. Most of the major features in the observed data are well explained by the models.

\section{Results and Interpretation Profile 1}

Figure 5(a) shows the resistivity structure for profile 1 for TM and TE modes. A clear low resistive zone is present to a depth of $3 \mathrm{~km}$ between sites 109 and 112. It is well interpreted as representing the sediments of the İzmit Bay basin. There is a less noticeable, relatively low resistivity layer dipping northwards between 5 and $15 \mathrm{~km}$ and bounded by highly resistive zones. The necessity for the inclusion of this low resistive zone was tested by examining a model in which we changed it to a zone of a higher resistivity value of $1000 \Omega \mathrm{m}$. The result of this test shows that the low resistive zone is required for better fitting to the observed data. The dipping feature might be a manifestation of the subducted slab of the Sakarya continent. Linear clustering of aftershocks passes through profile 1 below site 111, as shown in Fig. 2, and also by the distribution of aftershocks shown in Fig. 5(a). Most of the aftershocks tend to be located in a resistive zone underlain by a lower resistivity zone. Such a feature was also found in the hypocentral area of the İzmit earthquake through the low-frequency data acquired additionally with different instruments especially designed for low frequencies (in preparation).

\section{Profile 2}

Figures 5(b) and 5(c) show the two-dimensional resistivity model for profile 2 for both the modes and for the TM mode only, respectively. There is a very low resistivity zone at a depth of $5 \mathrm{~km}$ near the southern end of the profile. This is comparable with young sediments which are visible at the northern end of the profile. Except for this, resistivity below the depth of $5 \mathrm{~km}$ is generally low throughout the profile. Although the sea effect was taken into consideration twodimensionally during the inversion process, the contribution of the sea effect should in fact be three-dimensional because of the geometry of the Armutlu peninsula. The induction arrows also suggest such an effect, especially at the southern stations for frequencies lower than $1 \mathrm{~Hz}$.

In order to check whether the $2 \mathrm{D}$ treatment in this region is reasonable or not, a modeling experiment was performed for $3 \mathrm{D}$ and $2 \mathrm{D}$ forward cases to compare their responses. For 3D forward modeling, we used the code developed by Mackie et al. (1993). The result of the experiment showed some interesting features as follows. (i) In both cases (2D and 3D), apparent resistivity values tend to increase as the frequency decreases. (ii) In both cases, the shape of the TM-mode curve is similar to each other and the distortion caused by the sea 
(a)

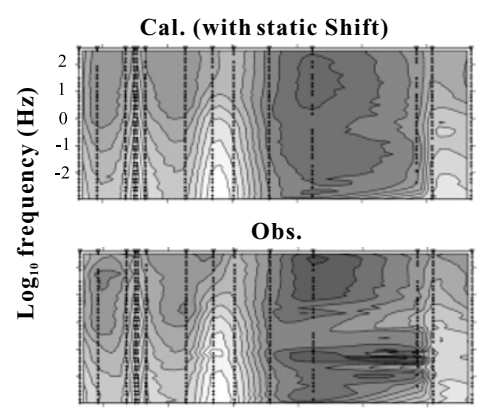

Cal.

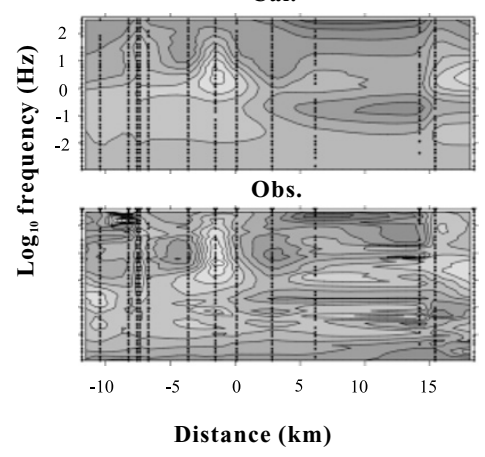

(b)

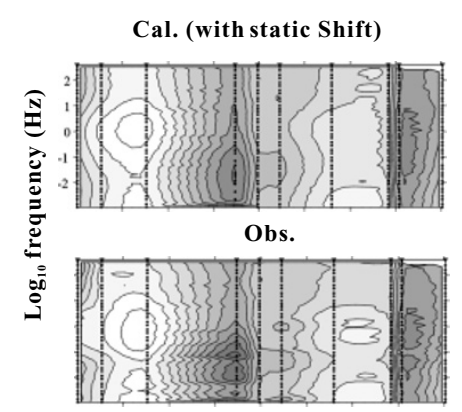

Cal.

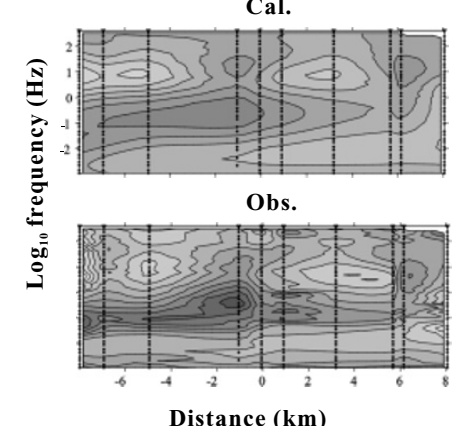

TE

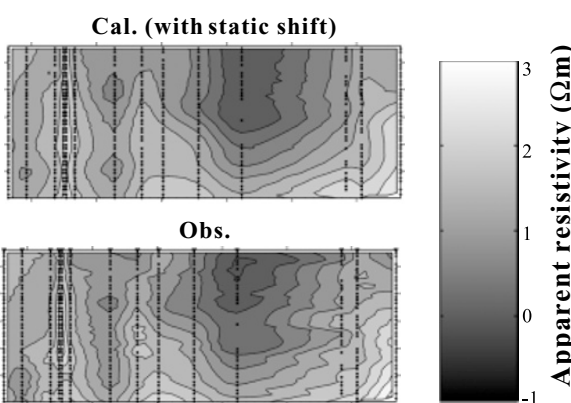

Cal.
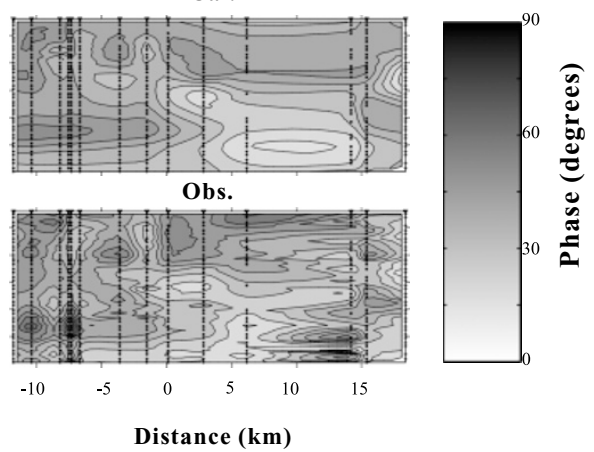

TE

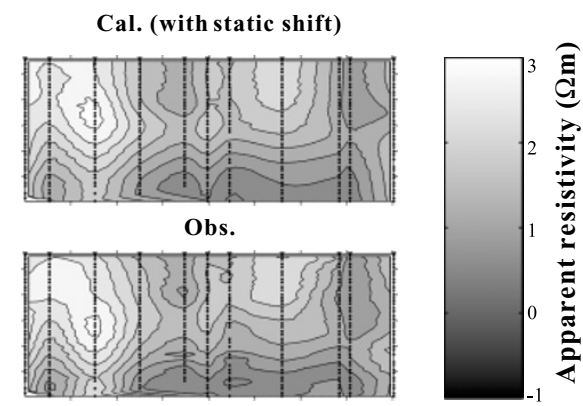

Cal.

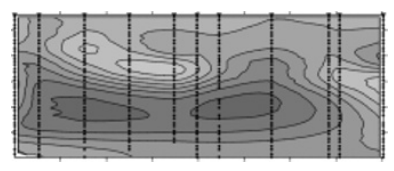

Obs.

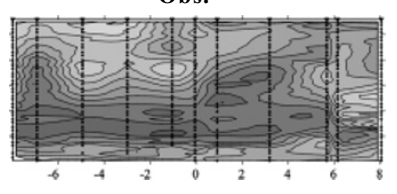

Distance (km)

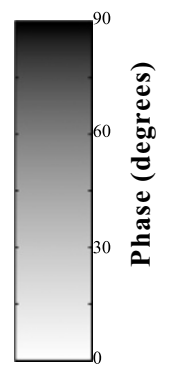

Fig. 4. (a) Pseudosections of the apparent resistivity and the phase for profile 1 . The observed and calculated values are shown for the TM and TE modes. (b) Pseudosections of the apparent resistivity and the phase for profile 2. The observed and calculated values are shown for the TM and TE modes.

effect appears at frequencies below $1 \mathrm{~Hz}$. (iii) In the $2 \mathrm{D}$ case, the TE-mode curves are more distorted than those in the 3D case. These results indicate that the 2D TM-mode gives a better approximation to a 3D area like the Armutlu peninsula than the combination of the 2D TM- and TE-modes. In fact, the 2D-3D responses are not significantly different from each other when only the TM mode is considered.
Small earthquakes located in the east of profile 2, as shown in Fig. 2, are characterized by a circular distribution. This activity is unlikely to correspond to the aftershocks of the İzmit earthquake. In fact, intermittent swarm-like activity had been noted in this area well before the Izmit earthquake (Barış et al., 2002). After the İzmit earthquake, the activity was more enhanced and spread toward profile 2 . In terms 
5a. TE+TM Mode

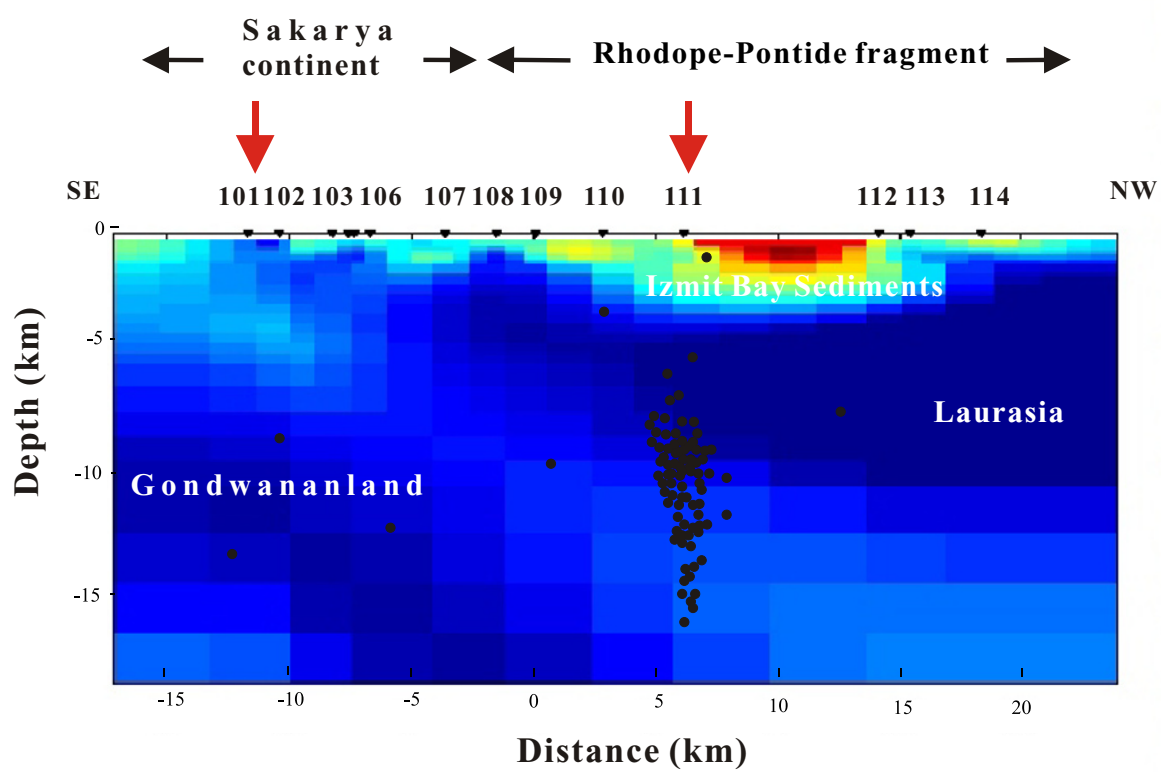

5b. TE+TM Mode

5c. TM Mode

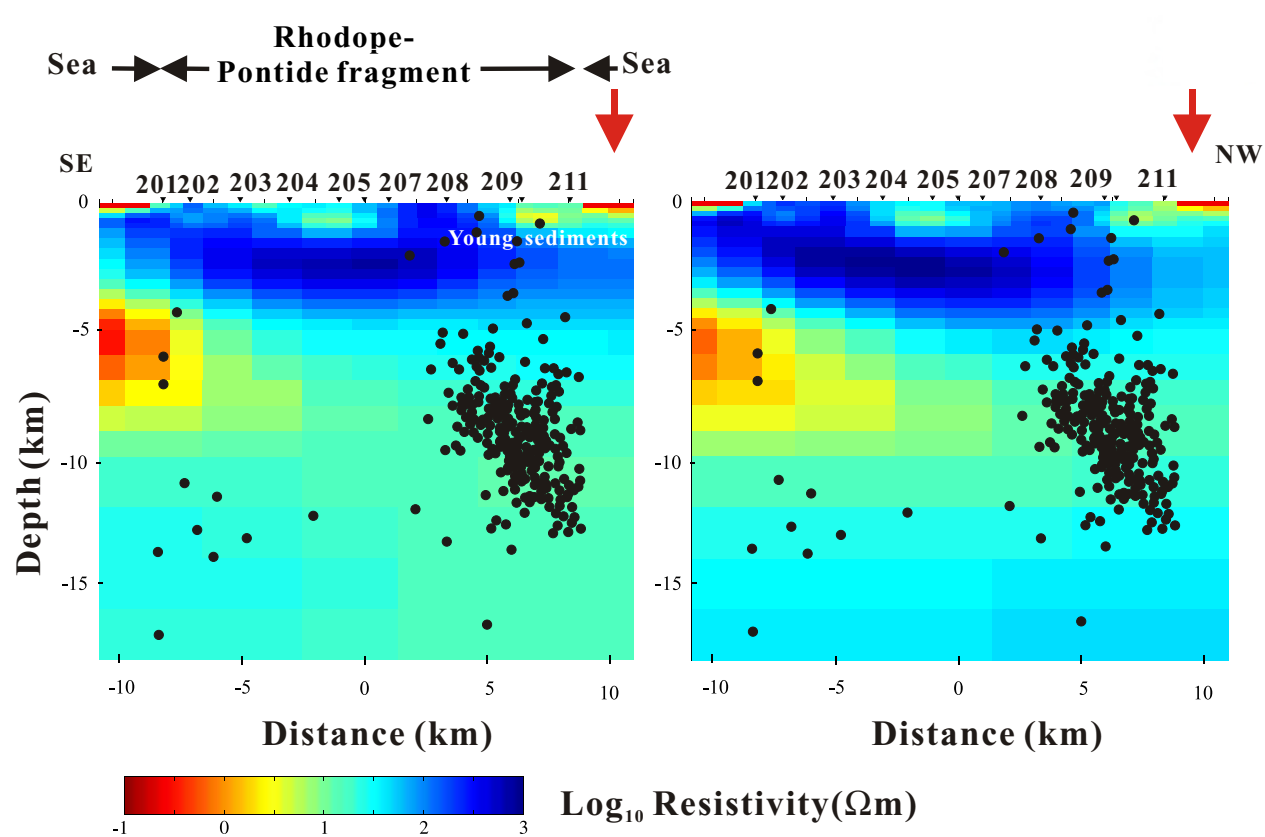

Fig. 5. (a) Two-dimensional resistivity structure along profile 1 derived from both the TM and TE modes. Triangles with numbers indicate the sites. Red arrows show the locations of the fault lines. Dots indicate aftershocks of the İzmit earthquake beneath the profile (Ito et al., 2002). (b) Two-dimensional resistivity structure along profile 2 derived from both the TM and TE modes. Triangles with numbers indicate the site. Red arrow shows the location of the fault line. Dots indicate small earthquakes in the swarm area. (c) Two-dimensional resistivity structure along profile 2 derived only from the TM mode. Triangles with numbers indicate the site. Red arrow shows the location of the fault line. Dots indicate small earthquakes in the swarm area (Ito et al., 2002).

of increased Coulomb failure stress due to the mainshock of the İmit earthquake, Pinar et al. (2001) interpreted the enhanced activity as triggered seismicity.

The low resistivity, as pointed out above, implies that crustal fluid must be contained in pores and cracks widely distributed in the upper crust in this area. Then we may expect an increase in pore pressure in association, for example, with an increase of Coulomb failure stress, resulting in the triggering of earthquakes. It should be noted here that the hydrothermal activity is also high, as indicated by the hot spring in this area (Eisonlohr, 1996).

\section{Conclusions and Discussion}

The most remarkable result in this study is the relation between the seismic activity and the resistivity structure. As for profile 1, aftershocks of the İzmit earthquake tended to occur in the resistive zone underlain by a moderately conductive zone. This feature is consistent with that in the hypocentral 
area of the İzmit earthquake (Honkura et al., 2000; Oshiman et al., 2002). Such a relation has also been noted in the seismically active areas in Japan (Mitsuhata et al., 2001; Ogawa et al., 2001, 2002). The porosity in this relatively conductive region can be estimated from Archie's law. The resistivity of $0.04 \mathrm{~m}$ can be assumed as a typical crustal fluid resistivity value (Nesbitt, 1993). The porosity estimated for $80 \Omega \mathrm{m}$ conductivity anomaly ranges between 0.4 and $2 \%$ when the cementation factor $(m)$ is taken as 1.3 to 2 .

However, we point out a seemingly important difference in the fault slip between the profile crossing the hypocentral area and profile 1 . In the former case, the fault slip amounted to $4 \mathrm{~m}$ or so, implying that the hypocentral area is classified as a strong asperity zone, whereas only a small slip was seen in the latter case (Yagi and Kikuchi, 2000). If the latter fault zone is weak so that some non-seismic slip must eventually occur or have occurred in the past, we would expect that the resistivity of such a weak zone is lower than the strong asperity area. For this kind of detailed discussion, however, we may need more detailed information on the fine structure of the fault zone.

As for profile 2, the resistivity is generally low in the earthquake swam area in mid-crust. This is a feature quite different from the other profiles. The swarm seems to be related to the crustal fluid existing in the low resistivity area. The fact that the swarm activity was enhanced by the occurrence of the Izmit earthquake implies the role of crustal fluid in triggering such seismic activity.

As discussed in this paper, the information on the resistivity structure is very important to investigate the characteristics of seismogenic zones in the crust. We have already made similar MT measurements in the eastern part of the İzmit earthquake rupture zone and its eastward extension, and plan to discuss the characteristics of the entire rupture zone associated with the İzmit earthquake.

Acknowledgments. We thank the many colleagues who participated in the field work. We also thank Martyn Unsworth and Hideki Murakami for valuable comments. This study was supported by the Ministry of Education, Science, Culture and Sports of Japan, under grant-in-aid for scientific research No.13373002. We are also grateful to THY (Turkish Airlines) and Atatürk Airport Customs Directorate for their kind help and support to our project.

\section{References}

Barış, S., A. Ito, S. B. Üçer, Y. Honkura, N. Kafadar, R. Pektaş, T. Komut, and A. M. Işıkara, Microearthquake activity before the Izmit earthquake in the eastern Marmara region, Turkey (1 January 1993-17 August 1999), Bull. Seismol. Soc. Am., 92, 394-405, 2002.

Bayrak, M. and S. S. Nalbant, Conductive crust imaged in western Turkey by MT, Geophys. Res. Lett., 28(18), 3521-3524, 2001.

Çağlar, I., Electrical resistivity structure of the northwestern Anatolia and its tectonic implications for the Sakarya and Bornova zones, Phys. Earth Planet. Inter., 125, 95-110, 2001.

Eisonlohr, T., The thermal springs of Armutlu peninsula (NW Turkey) and their relationship to geology and tectonic, in Active Tectonics of Northwestern Anatolia: The Marmara Poly-Project, Edited by C. Shindler and M. Pfister, Cambridge Publications, pp. 197-228, 1996.
Gamble, T. D., W. M. Goubau, and J. Clarke, Magnetotellurics with remote magnetic reference, Geophysics, 44, 53-68, 1979.

Groom, R. W. and R. C. Bailey, Decomposition of magnetotelluric impedance tensors in the presence of local three dimensional galvanic distortions, J. Geophys. Res., 94, 1913-1925, 1989.

Gürer, A., Deep conductivity structure of the North Anatolian Fault Zone and the Istanbul and Sakarya Zones along the Golpazari-Akcakoca profile, Northwest Anatolia, Int. Geology Review, 38, 727-736, 1996.

Honkura, Y., A. M. Ișikara, N. Oshiman, A. Ito, B. Üçer, S. Bariș, M. K. Tunçer, M. Matsushima, R. Pektaş, C. Çelik, S. B. Tank, F. Takahashi, M. Nakanishi, R. Yoshimura, Y. Ikeda and T. Komut, Preliminary results of multidisciplinary observations before, during and after the Kocaeli (Izmit) earthquake in the western part of the North Anatolian Fault Zone, Earth Planets Space, 52, 293-298, 2000.

Ito, A., B. Üçer, S. Barış, A. Nakamura, Y. Honkura, T. Kono, S. Hori, A. Hasegawa, R. Pektaş, T. Komut, and A. M. Işıkara, Aftershock activity of 1999 Izmit earthquake, Turkey, revealed from microearthquake observations, Bull. Seismol. Soc. Am., 92, 418-427, 2002.

Kasaya, T., N. Oshiman, N. Sumitomo, M. Uyeshima, Y. Iio, and D. Uehara, Resistivity structure around the hypocentral are of the 1984 Western Nagano Prefecture earthquake in central Japan, Earth Planets Space, 54, 107-118, 2002.

Mackie, R. L., T. R. Madden, and P. E. Wannamaker, Three-dimensional magnetotelluric modeling using finite difference equations-Theory and comparisons to integral equation solutions, Geophysics, 58, 215-226, 1993.

Mitsuhata, Y., Y. Ogawa, M. Mishina, T. Kono, T. Yokokura, and T. Uchida, Electromagnetic heterogeneity of the seismogenic region of 1962 M6.5 Northern Miyagi Earthquake, northeastern Japan, Geophys. Res. Lett., 28, 4371-4374, 2001.

Nesbitt, B. E., Electrical resistivity of crustal fluids, J. Geophys. Res., 98, 4301-4310, 1993

Ogawa, Y. and T. Uchida, A two-dimensional magnetotelluric inversion assuming Gaussian static shift, Geophys. J. Int., 126, 69-76, 1996.

Ogawa, Y., M. Mishina, T. Goto, H. Satoh, N. Oshiman, T. Kasaya, Y. Takahashi, T. Nishitani, S. Sakanaka, M. Uyeshima, Y. Takahashi, Y. Honkura, and M. Matsushima, Magnetotelluric imaging of fluids, in intraplate earthquake zones, NE Japan back arc, Geophys. Res. Lett., 28, 3741-3744, 2001.

Ogawa, Y., S. Takakura, and Y. Honkura, Resistivity structure across Itoigawa-Shizuoka tectonic line and its implications for concentrated deformation, Earth Planets Space, 54, 1115-1120, 2002.

Oshiman, N., R. Yoshimura, T. Kasaya, Y. Honkura, M. Matsushima, S. Bariş, C. Çelik, M. K. Tunçer, and A. M. Işikara, Deep resistivity structure around the fault associated with the 1999 Kocaeli earthquake, Turkey, in Seismotectonics in Convergent Plate Boundary, edited by Y. Fujinawa and A. Yoshida, pp. 293-303, Terra Sci. Publ. Company, Tokyo, 2002.

Pınar, A., Y. Honkura, and K. Kuge, Seismic activity triggered by the 1999 Izmit earthquake and its implications for the assessment of future seismic risk, Geophys. J. Int., 146, F1-F7, 2001.

Unsworth, M. J., P. A. Bedrosian, M. Eisel, G. D. Egbert, and W. Siripunvaraporn, Along strike variations in the electrical structure of the San Andreas Fault at Parkfield, California, Geophys. Res. Lett., 27, 3021-3024, 2000.

Yagi, Y. and M. Kikuchi, Source rupture process of the Kocaeli, Turkey, earthquake of August 17, 1999, obtained by joint inversion of near-field data and teleseismic data, Geophys. Res. Lett., 27, 1969-1972, 2000.

Yılmaz, Y., S. C. Genç, E. Yigitbaş, M. Bozcu, and K. Yılmaz, Geological evolution of the late Mesozoic continental margin of Northwestern Anatolia, Tectonophysics, 243, 155-171, 1995.

Zhao, D., H. Kanamori, and H. Negishi, Tomography of the source area of the 1995 Kobe earthquake: evidence for fluids at the hypocenter? Science, 274, 1891-1894, 1996.

S. B. Tank (e-mail: tank@geo.titech.ac.jp), Y. Honkura, Y. Ogawa, N Oshiman, M. K. Tunçer, M. Matsushima, C. Çelik, E. Tolak, and A. M. Iş1kara 